aseptic grooved needle did not find blood below the dura mater, so the wound was washed out with warm perchloride solution and closed with silkworm gut sutures, which at the base hospital were kept permanently in 1 in 20 carbolic acid solution. Though this clot was found and removed, and though there was a distinct improvement of intelligence and some return of power to the biceps muscle on August 7th, I was anxious about the patient as I could not reconcile the production of so marked a brachial and facial monoplegia with a clot compressing the motor area for the lower limb, which was absolutely unaffected. I was therefore prepared to trephine again lower down on the first indication of compression persisting over the brachial and facial area. On August 8th the patient was conscious, answering questions slowly but sensibly. The paralyses were the same. The right pupil was more dilated and was still immobile. The pulse was 90 and the temperature was $100 \cdot 8^{\circ}$. At 2 P.M. he suddenly became unconscious with stertorous breathing and a hot, sweating skin, and at 2.30 P.M. he had a spasmodic seizure of the right side of the face, both eyelids, and the right arm and forearm. The forearm was flexed and the wrist was flexed on the forearm, the thumb was forcibly pressed into the palm, and the fingers were clenched on it. Both eyes were twisted to the right and both pupils were widely dilated and immobile. This spasm lasted till 3 P.M., when the twitchings gradually ceased, the face being the first to recover. At 3.30 P.M. I again applied the trephine, having reopened and enlarged the old wound downwards. It was united by first intention. Two discs of bone were removed, one over the middle third of Rolando's line and the other on the same plane but in front of the line. The intervening bone between these two discs and the old one was removed by Hey's saw and bone forceps. It was then found that an angular piece of the inner table had been fractured, the angle pointing downwards and being almost directly over the fissure of Rolando. The sides, formed by fissured fractures, extended upwards on either side of the line over the ascending parietal and ascending frontal convolutions. From these fissures venous oozing had occurred resulting in a circumscribed clot of the size of a walnut lying over the middle third of the Rolandic fissure and the adjacent convolutions. There was no hæmorrhage below or wound of the dura mater, or evidence that the fracture of the inner table was sufficiently depressed to compress the brain. The clot was removed and the wound was closed as before. The course of the case after this was uneventful. The patient did not recover consciousness. He had no further spasmodic attacks but he gradually sank into a deeper and deeper state of coma and died on August 13th. I was exceedingly anxious to obtain a post-mortem examination, but Somali superstition was deaf to the voice of science, his comrades objected and my case was left incomplete.

Stationed 800 miles from civilisation and nearly as many thousand miles from a medical library I cannot now refer to the literature of this subject, but I believe that fracture of the inner table of the skull with no discernible injury to the outer is of sufficiently rare occurrence to warrant the publication of this case. That the splintering of the inner table did not radiate from the point of impact of the bullet is peculiar, but is not inconsistent with the theory of diffusion of force widely over the table not directly struck. I certainly expected to find a star-shaped fracture immediately beneath the point struck by the bullet, and this expectation led me to trephine there and not over the brachial area in the first instance. I do not think that by so doing the result would have been altered, as it is probable that severe laceration of the brain substance, if not a fracture of the base extending across the anterior fossa, was present. The occurrence of epistaxis would suggest the latter. Certainly the tremendous energy of a Martini-Henry bullet, striking the skull at five yards from the muzzle, would be sufficient to produce either lesion. Unyoro, East Africa.

BARRY SCHOOL BOARD.-The triennial election of the Barry School Board took place on Nov. 18th, when nine members were elected. Of their number three were members of the medical profession-viz.: Mr. Peter J. O'Donnell, L.R.C.S. Irel., Mr. John L. Livingston, M.D. C.M. Glasg., and Mr. William Lloyd Edwards, L.R.C.P. Lond., M.R.C.S. Eng. The first-named of these gentlemen was returned at the head of the poll.

\section{CURE OF LEFT CAROTID ANEURYSM BY MANIPULATION.}

BY RICHARD SLOCOCK, B.A. OXON., M.R.C.S. ENG., L.R.C.P. LOND.,

HOUSE BURGEON TO THE ROYAL PORTSMOUTH HOSPITAL.

A MAN, aged twenty-eight years, healthy, of spare build, was admitted into the Royal Portsmouth Hospital, under the care of Dr. Lloyd Owen, on Sept. 14th, 1897, with a wellmarked aneurysm of the left common carotid artery. $\mathrm{He}$ stated that a swelling, which gave him no inconvenience beyond a little neuralgia, had existed six weeks before admission. There was no history of injury or of syphilis. The pupils were symmetrical and normal. The swelling was situated near the bifurcation of the common carotid artery and was of about the size of a pigeon's egg with most definite expansile pulsation both seen and felt. This ceased on compressing the artery below. Its walls were so thin that an immediate operation was indicated. The patient, who was a nervous and apprehensive man reluctantly consented to an operation. It was decided to ligature the artery below the sac. The patient, however, suddenly took alarm and obstinately refused to have any surgical treatment. It seemed dangerous for him to even move under his present condition. He left the hospital on Sept. 18th and sudden rupture of the aneurysm was feared. No more was heard of him until February, 1898, five months afterwards, when Mr. Bond, of Havant, to whom am indebted for the following notes, wrote "that a few days after his return from the hospital he examined him, and to illustrate the nature of the operation necessary for cure he pressed firmly over the sac and artery. When next seen. two days afterwards, the beating in the neck had ceased and

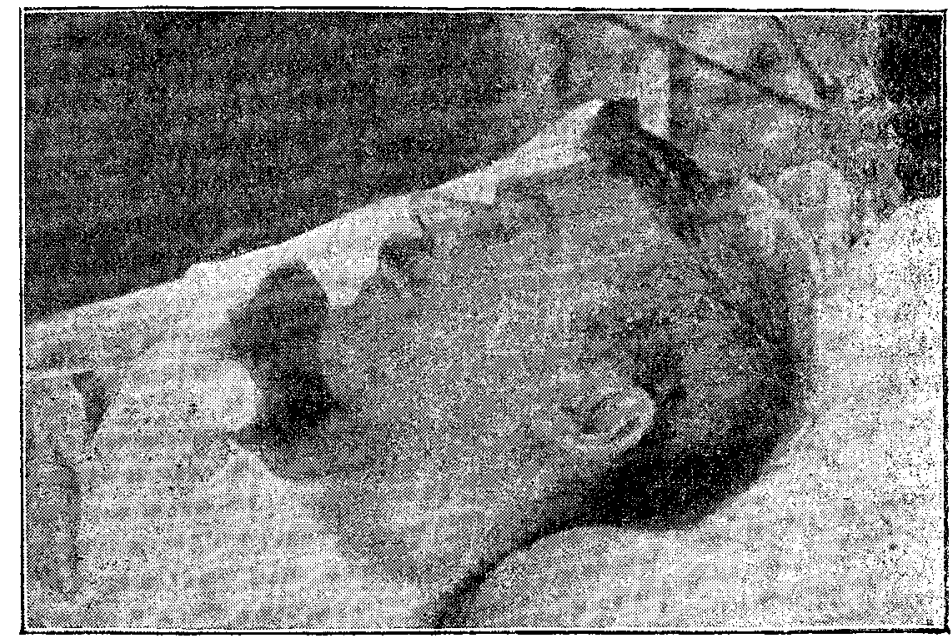

Illustration showing aneurysm of carotid.

never returned. The tumour gradually diminished." And writing in April Mr. Bond reports: "There is not the least vestige of the aneurysm. It is completely cured. ..... He is quite well and in regular employ."

This case may, I think, be regarded as a cure of carotid aneurysm, effected in an unintentional and unexpected manner by manipulation, a method introduced by Sir William Fergusson in 1862. Probably, when the aneurysm was being examined a detached clot became impacted in the mouth of the sac and acted as a check to the circulation. Such a happy termination to such a serious case must be rare, and is therefore of sufficient interest to be recorded as a welcome accident and not as a mode of treatment to be followed. No one would, except by accident, employ such treatment in aneurysm at the root of the neck, for the fear of producing head symptoms from embolism of the cerebral arteries must be very great. Two cases are reported ${ }^{1}$ in which the examination for diagnostic purposes of carotid aneurysm produced paralysis and death. This case confirms the observation ${ }^{2}$ that carotid aneurysm is more common in men than in women (of 88 cases of this disease 55 were those of men and 28 those of women, the sex in 5 not

1 Virchow's Archiv, Band xi.; Medical Times and Gazette, vol, i. 1859. 2 Ashhurst's Surgery, vol, iii., p. 496. 
being stated) and also that a very large proportion of cases of aneurysm of the carotids, $87 \cdot 25$ per cent., belongs to the common carotid at or near the bifurcation.

My thanks are due to Dr. Lloyd Owen for permission to publish the case and to my colleague, Mr. C. H. Newby, for the illustration.

Portsmouth.

\section{INJECTION OF SALINE SOLUTION IN SHOCK.}

BY W. THELWALL THOMAS, F.R.C.S. ENG.,

ONORARY ASSISTANT SURGEON TO THE LIVERPOOL ROYAT INFIRAARY ASSISTANT LECTURER IV SURGERY, UNIVERSITY COLLEGE, LIVERPOOL.

WHEN an animal is killed by bleeding all the blood does not escape, yet the animal dies. The quantity remaining in the tissues, although containing a large number of blood cells, is of no use because it ceases to circulate, a small stream being unable to travel by reason of the great inequality between its size and that of the large vessels. The heart has little or nothing to contract upon, and even if a little blood gets into the large arteries the vessels cannot pass it along. The more sudden the loss-i.e., the larger the divided vessels--the quicker the collapse and death; slow loss of blood allows time for transudation of fluid into the vessels from the tissues and thus enables the circulation to be quietly, though often very feebly, carried on. In surgical cases where large vessels are divided serious collapse may be produced, or even death. In the serious cases the pulse becomes imperceptible at the wrist, the skin ghastly pale, the lips and mucous membranes almost white, and failure of respiration heralds death. In such an alarming sequence promptitude on the part of the surgeon may avert a fatality. What he has to do is to quickly stop the leak (if possible) and provide the necessary blood or liquid.

Transfusion of arterial or venous blood necessitated a hero or heroine willing to part with the requisite amount and a cumbersome, complicated apparatus. These conditions were not often found together and even when they were only occasional good results were recorded, for the mortality was very high. Experimental research demonstrated that coagulation emboli were the cause of death. Blood from the lower animals always produced disintegration of the corpuscles, so its use was quickly abandoned. In 1862 Nussbaum $^{2}$ suggested defibrinated blood to diminish the risk of emboli, but its preparation in an emergency being somewhat tedious and necessitating several processes soon placed it out of court. Goltz recognised the salient fact that death from loss of blood was really due to loss of liquid from the vascular system, and that any suitable solution-e.g., saline solution or artificial serum-would do for injection. This was an important advance. It is only within recent years that the practical application of the truth has been realised and the lectures delivered by Dr. Wm. Hunter in 1889 at the Royal College of Surgeons of England ${ }^{2}$ had a large share in emphasising it. He showed (1) that the immediate source of danger from sudden loss of blood is the rapid fall in blood pressure; (2) that the value possessed by transfused blood is almost solely physical and dependent upon its volume; and, lastly, that all the advantages of transfused blood can be more readily and safely obtained by the use of simple saline solution. Normal saline solution, 6 parts of sodium chloride to 1000 parts of sterilised water, promptly injected into the renous system, will wash up the stranded corpuscles and give the heart something to contract uponliquid within-its normal stimulus, and enable the circulation to be carried on and the oxygenation of the red blood cells to proceed. If the patient be not too old, manufacture of new blood cells goes on rapidly and in a few hours the change produced is little short of marvellous, and anyone for the first time seeing a patient saved even when apparently at his last gasp will be astonished at the effect.

The emergency method of dissolving a teaspoonful of common salt in a pint of hot water gives about 1 in 875 , but for all practical purposes it is near enough. When patients

1 Iredical Times and Gazette, vol. i., 1862, p. 600 .

2 Quoted by Erichsen: Science and Art of Surgery, tenth edition, are only suffering some degree of collapse short of imminen peril the solution may be injected into the rectum. In the same way hot saline solution left in the peritoneal cavity during abdominal operations produces rapid improvement in the patients. The fluid may be injected by pressure into the cellular tissue, under the mammary gland, in the groin or in the axilla, and by becoming absorbed takes the place of the lost liquor sanguinis, but all these methods are only serviceable when circulation is proceeding and absorption possible, and are of necessity slower in their action than injection into the veins direct. In extremis, nothing short of salt solution directly into a vein is of any use. For this purpose the apparatus generally used by me consists of a glass syringe (capacity $4 \mathrm{oz}$.), $2 \mathrm{ft}$. of rubber tubing, and a curved meta canula to fit a vein of the size of the median basilic vein. The wad of the piston is made of sterilised gauze; the material generally found on the piston when it leaves the maker's hands consists of white, clean looking material in the superficial layers, but "abominations" underneath in the shape of common-very common-tow, a whited sepulchre in truth. The piston is withdrawn and the whole apparatus filled with salt solution before fitting the canula into the vein, to prevent, of course, entrance of air into the venous system. The canula is tied into the vein selected and the syringe is elevated; if the fluid does not run in quickly enough the piston is inserted and the solution is forced in. A finger-and-thumb clamp of the tubing at the nozzle of the syringe enables the syringe to be withdrawn, filled again, and reapplied, and so on until enough fluid has been forced in. I have used a Higginson's syringe as the motive power. The following three cases illustrate the value of resort to saline injection.

CASE 1.-On Oct. 5th, 1894, a man was brought to the Liverpool Royal Infirmary on a police ambulance with his " throat cut." The out-patient clinique was being conducted at the time, so no delay occurred, although half-an-hour must have elapsed since the incision had been made. The man was unconscious, deathly white in colour, and pulseless, even in the exposed cut common carotid. The lower jaw spasmodically dropped with a feeble inspiratory effort. There was a deep gash in the left side of the neck. The internal jugular vein was cut clean through, the cut ends being three-quarters of an inch apart; the common carotid was cut into and the external and anterior jugular veins were divided. There was no blood escaping from the cut vessels; he had lost all the blood which it was possible to lose. The cut vessels were clamped; a small jerk of blood -less than a teaspoonful-escaped, however, when the common carotid was clamped. He seemed to be as near death as it was possible to get. I exposed the left median basilic vein by an incision to which the patient did not object-being no doubt " too far gone"-and $20 \mathrm{oz}$. of normal saline solution were slowly injected. After $7 \mathrm{oz}$. he took a short, distinct, inspiration; at $10 \mathrm{oz}$. a deeper one; the carotid was noticed to pulsate at $15 \mathrm{oz}$. and his breathing became regular and deep; and at $18 \mathrm{oz}$. he opened his eyes but did not appear to be conscious. His radial pulse was distinctly felt. The injection was stopped, all the clamped vessels were tied and a dressing was hurriedly applied. Thus far the treatment had been carried out on the ambulance, elevated at the foot. He was then wheeled to bed, surrounded by hot water bottles, and the foot of the bed was raised $18 \mathrm{in.}$ An hour later he had sufficiently recovered to answer when called loudly to. He rapidly improved in condition. On Nov. 5th, owing to secondary bæmorrhage, he became collapsed. A quart of hot saline solution was injected into his rectum; all of it was absorbed and acted most beneficially in reviving him. This patient died two and a quarter years later and the unique dissected specimen of the neck is in the museum of University :College, Liverpool.

CASE 2.-A man, aged twenty-five years, had to lose his leg and part of his thigh on account of extensive suppurative (gummatous) disease of the knee-joint. The operation was perforce performed through diseased tissues by Mr. Hamilton on Oct. 13th, 1896. The flaps were loosely brought together. The stump appeared to be healing well when, on Nov. 2nd, the twentieth day, at 8 P.M., he suffered from severe secondary hæmorrhage. The ward sister promptly applied a tourniquet, but he had lost a large quantity of blood. The house surgeon, Dr. Graham Martin, on being summoned, realised the extreme gravity of the case. In the absence of Mr. Banks and Mr. Hamilton I hurried to the Infirmary. The patient was very much emaciated 